\title{
HBsAg, chronic lymphoproliferative disorders, and cirrhosis of liver
}

\author{
R. HEIMANN, M. B. RAY, AND V. J. DESMET
}

From the Department of Pathology, Institut Jules Bordet, University of Brussels, B.1000 Brussels, and the Laboratory of Histochemistry and Cytochemistry, Akademisch Ziekenhuis Sint-Rafaël, University of Leuven, B.3000 Leuven, Belgium

SUMMARY This study reports the incidence of HBsAg in a series of chronic lymphoproliferative disorders in which a high incidence of cirrhoses had been previously observed. Twenty-three cases were collected from the necropsy records. The type of lymphoma was reviewed in the light of the new functional classifications of non-Hodgkin malignant lymphomas introduced by Lennert and Lukes. The presence of HBsAg in the liver was investigated by the indirect immunofluorescence technique. Eleven cases showed plasmocytoid features and were considered as immunocytomas. Seven cases showed cirrhosis of the liver; six of them belonged to the immunocytoma group. Four cases were positive for HBsAg. Three of them were found among the group combining cirrhosis and immunocytoma. They presented the abundant nodular distribution of $\mathrm{HBsAg}$ typical of inactive cirrhosis.

A parallel is drawn between the often reported association of Waldenström's syndrome and cirrhosis and the association of immunocytoma and cirrhosis observed in this study. The analogy is all the more justified since most of the lymphomas associated with Waldenström's syndrome happen to be immunocytomas. Therefore the association between HB virus infection and cirrhosis on the one hand and chronic lymphoproliferative disorders on the other may not be purely coincidental. A chronic antigenic stimulus such as persisting HBsAg could trigger the proliferation of a malignant lymphoid clone.

The detection of hepatitis $\mathrm{B}$ antigen (HBsAg) in the serum and the liver has greatly advanced our understanding of the pathogenesis of hepatitis B. An important step was the identification by Nowoslawski et al. (1970) of HBsAg in the hepatocytes of patients with lymphoproliferative disorders. They were struck by the scantiness of liver damage in these cases and pointed out the discrepancy between the number of infected cells and the extent of cellular damage. The cases with stigmata of chronic persistent hepatitis, the severest changes observed in their study, presented the lowest percentage of hepatocytes harbouring HBsAg. The absence of pronounced alterations was ascribed to a state of tolerance due to an impaired immune system.

Morphological studies of the liver of patients with immune deficiency have lately focused on kidney transplant recipients (Gudat et al., 1975). Ray and Desmet (1975) discovered that the immunofluores-

Received for publication 30 December 1976 cence technique for the detection of HBsAg can also be applied to paraffin-embedded tissue. This technique allows retrospective investigations of necropsy material. The finding by the same group (Ray et al., 1976a) that $\mathrm{HBsAg}$ is more readily demonstrated in the hepatocytes than in the serum obviates the lack of serological information in older cases.

Chronic lymphoproliferative disorders remain the most common spontaneous diseases with immune deficiency. Since we had already found a high incidence of liver cirrhosis in our necropsy records of chronic lymphoproliferative disorders (Heimann, $1971 \mathrm{a}, \mathrm{b}, \mathrm{c})$ it obviously became of interest to find out the incidence of $\mathrm{HBsAg}$ in these cases. We therefore selected for study the cases diagnosed either as chronic lymphocytic leukaemia or as well-differentiated lymphocytic lymphoma according to Rappaport's classification (1966). We also took the opportunity to review these cases in the light of the new functional classifications of non-Hodgkin lymphomas introduced by Lennert et al. $(1975 \mathrm{a}, \mathrm{b})$ 
and by Lukes and Collins (1974, 1975), which have many points in common.

\section{Material and methods}

Twenty-three cases were collected from the necropsy files. The histology of the liver was studied in each case by conventional staining, including Masson's trichrome, and by the indirect immunofluorescence technique for HBsAg (Ray and Desmet, 1975). The clinical notes of the cases showing positive immunofluorescence were reviewed and pertinent data recorded. As to the lymphomas sections from lymph nodes, bone marrow, and spleen were stained with Giemsa and periodic acid Schiff (PAS) after diastase digestion.

Two among the innovations in the new classifications of Lennert and Lukes are particularly relevant to this work. The first is the lumping in one single group of chronic lymphocytic leukaemia and well differentiated lymphocytic lymphoma, which are considered merely as two different growth patterns of the same neoplastic cell line. The second is the distinction in this group between a form without and a form with plasmocytoid differentiation. The former is called malignant lymphoma, small lymphocyte type, by Lukes or chronic lymphocytic leukaemia (CLL) by Lennert, whereas the latter is labelled plasmocytoid lymphocyte type by Lukes or, more simply, immunocytoma by Lennert. The hallmark of immunocytomas is the presence in the nucleus or the cytoplasm of PAS-positive, diastase-resistant globularo․ inclusions which yield evidence for immunoglobulin synthesis.

Lennert found in his series that one-third of the immunocytoma cases showed an increase of the $\frac{\bar{D}}{\bar{D}}$ immunoglobulin content in the serum, which was $\frac{\bar{\sigma}}{\bar{\phi}}$ monoclonal in some cases. The relatively small $\stackrel{\complement}{\complement}$ proportion of secreting immunocytomas is ascribed $ळ$ to the fact that most of these lymphomas synthesize $\overrightarrow{-}$ immunoglobulins without being able to excrete them in the serum. Nevertheless, in Lennert's series $\vec{\omega}$ immunocytomas represent the predominant group of 2 lymphomas associated with Waldenström's macro-요 globulinaemia.

\section{Results}

Four out of the 23 cases presented indirect fluor-음 escence for HBsAg (Table). Case 1 was a 58-year-old $-\overrightarrow{ }$ man whose leukaemia was diagnosed in 1970. $\mathscr{D}$ Because of anaemia and thrombocytopenia he received repeated blood transfusions and developed 3 stigmata of haemosiderosis. There was no history of ${ }_{\mathbb{\Phi}}^{\widetilde{D}}$ previous hepatitis. He died in heart failure in 1972. His liver showed CLL infiltration and, in addition $8 \%$ iron deposition, there were discrete cellular lesiós. consistent with a resolving hepatitis. Fluorescee staining showed a spotty distribution of $\mathrm{HBsAg}$ the cytoplasm and the membranes of a few hepato-

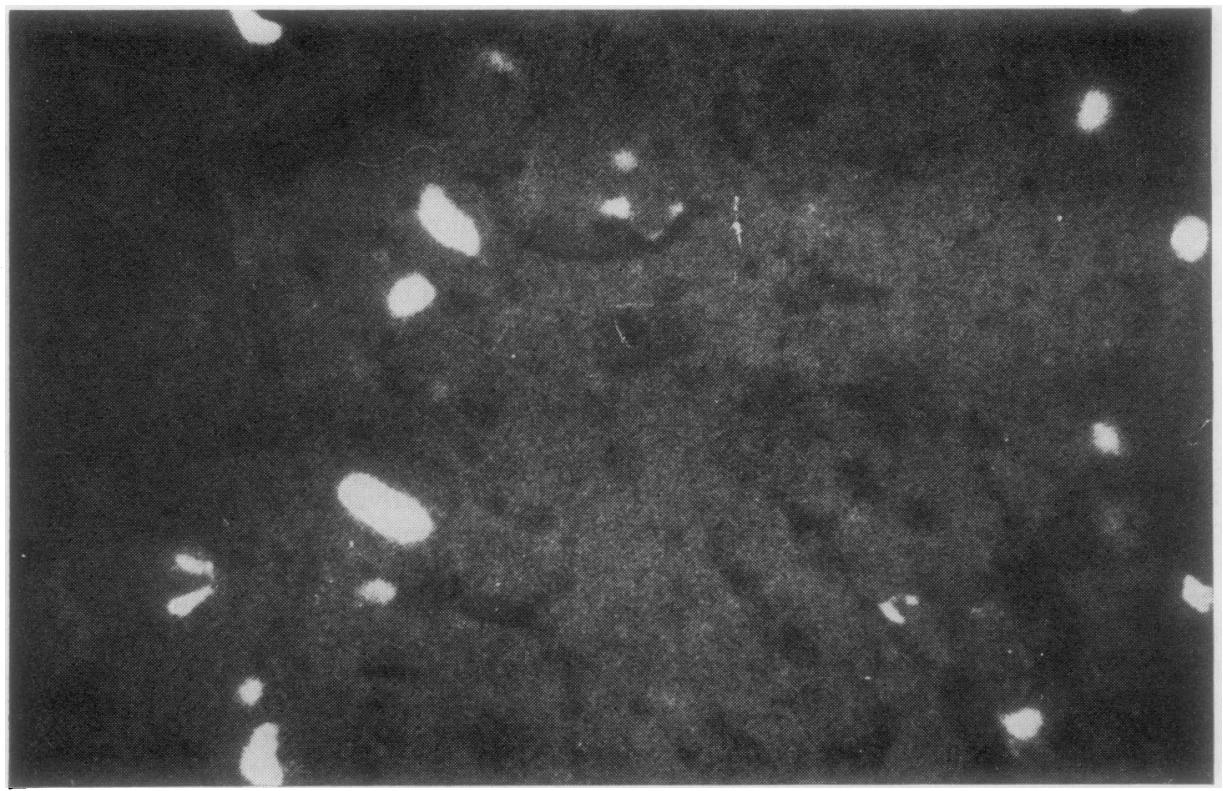

Fig. 1 Case 1. Spotty fuorescence of HBsAg in cytoplasm and membranes of a few hepatocytes. $(\times 176)$ 
Table Incidence of HBsAg in cirrhotic and non-cirrhotic cases according to the type of lymphoma

\begin{tabular}{|c|c|c|c|c|c|}
\hline \multirow[t]{2}{*}{ Type } & \multirow[t]{2}{*}{ No. of cases } & \multicolumn{2}{|l|}{ Cirrhosis } & \multicolumn{2}{|c|}{ Non-cirrhosis } \\
\hline & & $H B s A g+$ & $H B s A g-$ & $H B s A g+$ & HBsAg- \\
\hline $\begin{array}{l}\text { Immunocytoma } \\
\text { Others (CLL + hairy cell leukaemia) }\end{array}$ & $\begin{array}{l}11 \\
12\end{array}$ & 3 & $\begin{array}{l}3 \\
1\end{array}$ & $\overline{1}$ & $\begin{array}{r}5 \\
10\end{array}$ \\
\hline Total & 23 & 3 & 4 & 1 & 15 \\
\hline
\end{tabular}

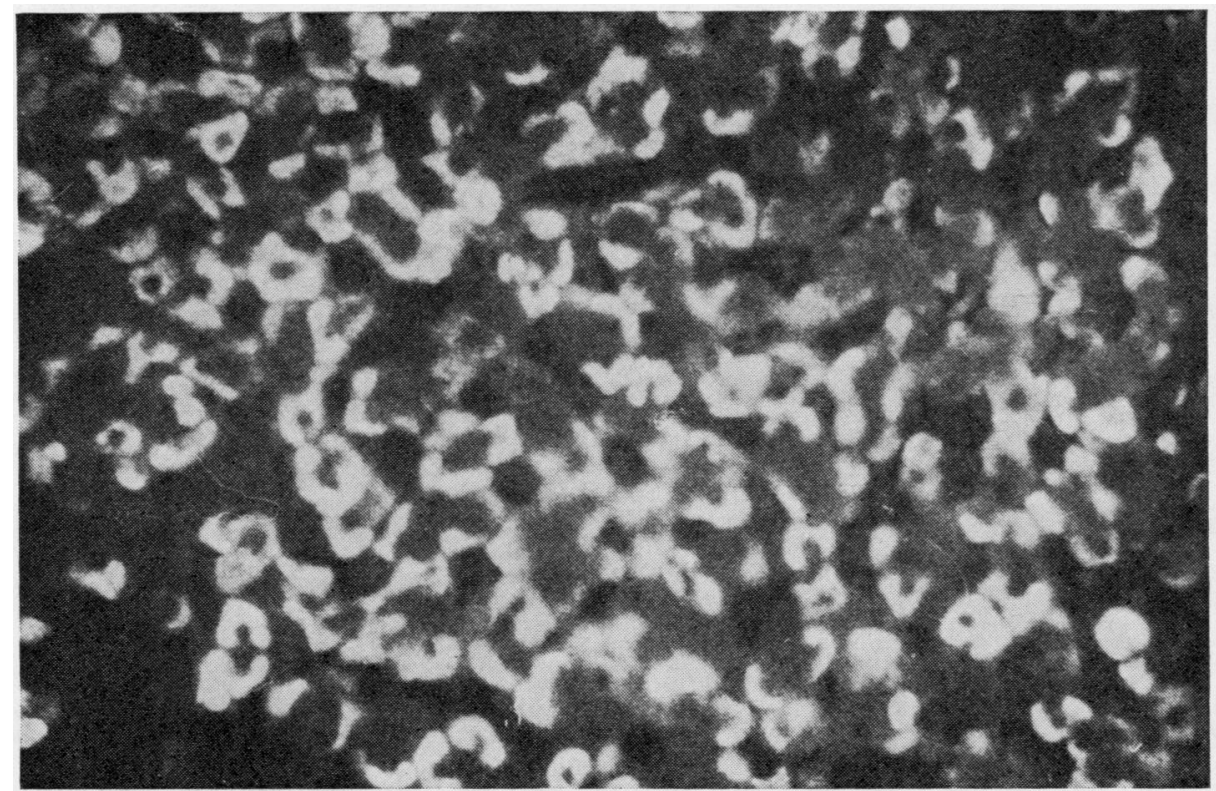

Fig. 2 Cases 2, 3, 4. Nodular distribution of HBsAg. Most hepatocytes of a cirrhotic nodule show bright cytoplasmic fluorescence. $(\times 176)$

cytes (Fig. 1).

Case 2, a man, was aged 76 years when he died in 1955. He was admitted for intestinal obstruction due to lymphomatous involvement of the bowel. There was no history of hepatitis and he had not received any chemotherapy.

Case 3, an 83-year-old woman with no previous history of hepatitis, was admitted to hospital in 1970 because of weakness and generalised lymphadenopathies. Four years previously a kidney tumour had been left untreated because of the patient's age. There was a blood picture of leukaemia and a monoclonal peak of IgG in the serum. She had supportive treatment only.

Case 4, a man, was aged 51 when his leukaemic condition was diagnosed in 1955 . For 9 years he was treated with various drugs (6-mercaptopurine, chlorambucil, triethylene melamine) together with corticosteroids and radiotherapy. A few months before his death in 1966 he developed jaundice, hepatomegaly, and ascites. These were attributed to leukaemic involvement of the portal lymph nodes. A single serum electrophoresis performed in 1961 showed only diffuse hypogammaglobulinaemia.

The pathology in the last three cases had several features in common. A cirrhosis was discovered incidentally which showed only discrete signs of aggression corresponding to a cirrhosis with little activity (Ray et al., 1976b). The cytoplasm of the hepatocytes presented a bright, homogeneous fluorescence with a nodular distribution typical for this type of cirrhosis (Fig. 2). Furthermore, the lymphomatous infiltrates in the liver and the lymphoid organs exhibited cells with PAS-positive, diastase-resistant inclusions and plasmocytoid features fulfilling the criteria of immunocytomas (Fig. 3).

In addition to these three cases there were four other cases of cirrhosis which were negative for HBsAg, but three of them were also cases of immunocytoma. In other words, in six of the seven cases of cirrhosis the lymphoma was an immunocytoma. 


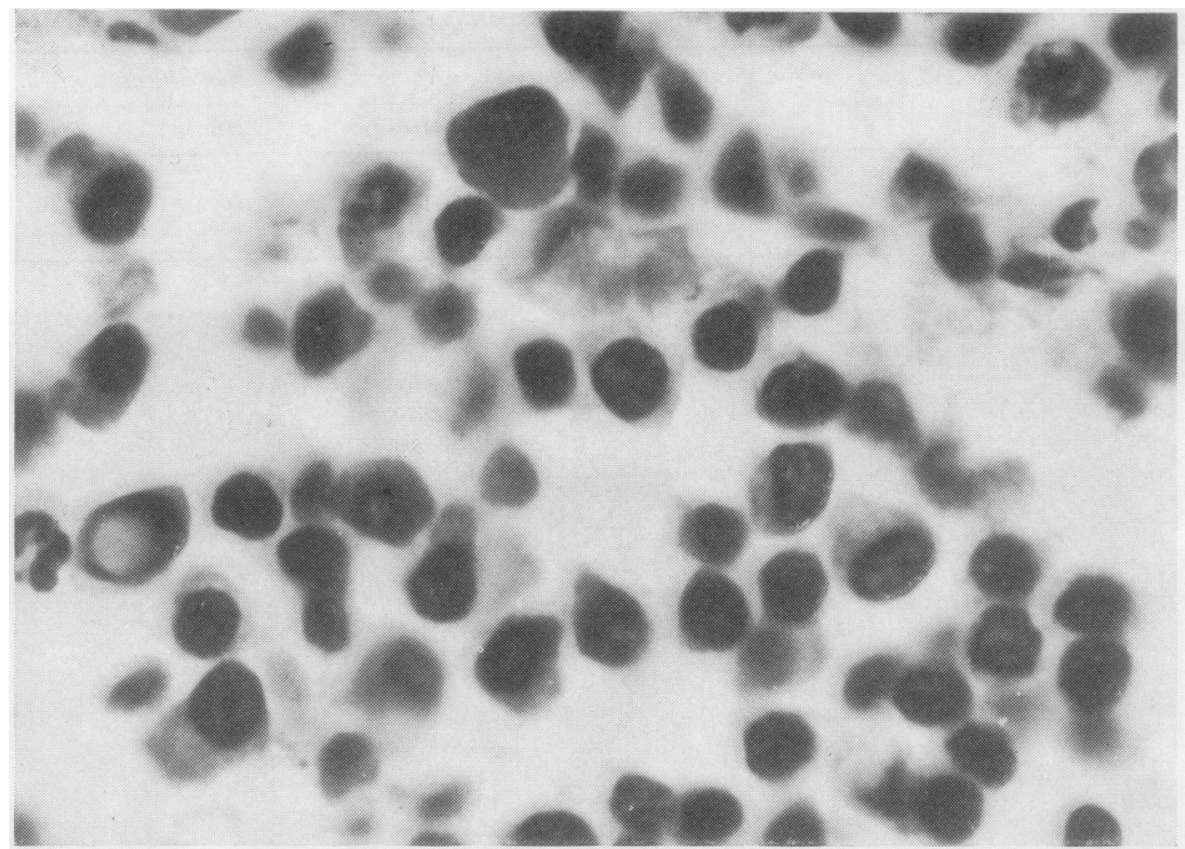

Fig. 3 Cases 2, 3, 4. Lymphomatous cells show obvious plasmocytoid features. Two cells contain a $P A S$-positive intranuclear inclusion. $(\times 704)$

The regrouping of the 23 lymphomas according to the new classifications yielded 11 cases of CLL, 11 of immunocytoma, and one of hairy cell leukaemia (Table).

\section{Discussion}

Nowoslawski et al. (1970) found only minimal liver damage in patients with lymphoproliferative diseases who harboured HBsAg in their hepatocytes. This was not the case in our series, where three out of the four patients with HBsAg showed definite alterations in the form of a cirrhosis-albeit a cirrhosis with little activity. Interestingly the pattern of $\mathrm{HBsAg}$ distribution was the same in the patient in case 4 who had had long-term chemotherapy as in the patients in cases 2 and 3 who were not treated.

At first sight these findings seem to contradict the conclusions of Nowoslawski et al. (1970) and imply that patients with lymphoproliferative disorders are not inevitably tolerant to HBsAg. However, since we have no information about the sequence between the lymphoma and the cirrhotic process there is no proof that the former preceded the infection with $\mathrm{HB}$ virus. The high incidence of cirrhosis among the lymphoproliferative disorders in our necropsy material has already been reported (Heimann, 1971a, b, c). The association between cirrhosis and lymphoprolifera- tive disorders, especially CLL ('Lymphadenosen'), is well known in Germany (Fischer, 1968; Fischer and Schaefer, 1972; Vykoupil and Georgii, 1972). It haso at times been linked to the treatment (Doerr, 1956; Bock et al., 1959) but it occurs independently of anyo therapy (Heimann, 1971a, c; Vykoupil and Georgii, 1972).

A reappraisal of our series of lymphomas accord ing to the new functional classifications of Lennerto and Lukes showed that the majority of those associated with a cirrhosis were in fact immunocytomas, which, in turn, are the most common forms of lymphomas associated with Waldenström's macroglobulinaemia (Lennert et al., 1975a, b). Interestingly,o papers on this syndrome and on gammopathies in general have repeatedly reported cases with livero cirrhosis. Waldenström (1961) himself noticed such instances. Whereas some authors like Hällen (1966) remained undecided about a possible relation between these two conditions, Eliakim et al. (1972) స్ల in their general review of gammopathies in liver diseases, thought that the occurrence of monoclonak gammopathy in cirrhosis might be attributed to an unidentified chronic antigenic stimulation.

This explanation is plausible, since we know that antibody production to antigen derived from both the gut and elsewhere is increased in cirrhosis, probably because the ability of the liver to trap antigen is़्D 
reduced (Walker, 1974). It is tempting to extend this concept and to suggest that in certain circumstances continuous antigenic stimulation, such as persisting $\mathrm{HBsAg}$, could not only initiate the production of a monoclonal gammopathy but could also trigger the proliferation of a malignant lymphoid clone.

In conclusion, there is some good evidence both from the literature and from our findings that a link exists between lymphoproliferative disorders and cirrhosis. In all likelihood their combination, especially in cases with abundant $\mathrm{HBsAg}$, is more than coincidental. The sequence suggested above is a working hypothesis, and an alternative chain of events cannot be ruled out. Prospective studies will probably clear up this problem.

We thank Dr J. D. Davies of Bristol, Dr J. Wybran of Brussels, and Professor K. Lennert, of Kiel for their helpful advice. We also thank Dr S. Levin of the Institut Bordet for reviewing the manuscript, Miss B. Smets and Mr G. Snel for technical help, and Mrs M. De Sloover for typing the manuscript.

\section{References}

Bock, H. E., Gross, R., Lambers, K., and Wulf, G.(1959). Leukämie und Leber. Medizinische, 29/30, 1325-1331.

Doerr, W. (1956). Pathomorphose durch chemische Therapie. Verhandlungen der Deutsche Gesellschaft für Pathologie, 39, 17-73.

Eliakim, M., Zlotnick, A., and Slavin, S. (1972). Gammopathy in liver disease. In Progress in Liver Disease, vol. IV, edited by H. Popper and F. Schaffner, pp. 403-417. Grune and Stratton, New York and London.

Fischer, R. (1968). Neue Aspekte der pathologischen Anatomie der Leukosen. Der Internist, 9, 457-465.

Fischer, R. and Schaefer, H. E. (1972). Die pathologische Anatomie der Leukosen. In Leukämie, edited by $\mathbf{R}$. Gross and J. Van De Loo, pp. 1-24. Springer, Berlin, Heidelberg, New York.

Gudat, F., Bianchi, L., Sonnabend, W., Thiel, G., Aenishaenslin, W., and Stalder, G. A. (1975). Pattern of core and surface expression in liver tissue reflects state of specific immune response in hepatitis B. Laboratory Investigation, 32, 1-9.

Hällen, J. (1966). Discrete gammaglobulin (M-) components in serum. Clinical study of 150 subjects without myelomatosis. Acta Medica Scandinavica supplement 462, $1-27$.

Heimann, R. (1971a). Cirrhoses et lymphopathies malignes. Acta Gastro-enterologica Belgica, 34, 663675.
Heimann, R. (1971b). Cirrhosis and lymphoproliferative disorders. (Letter.) Lancet, 2, 101.

Heimann, R. (1971c). Cirrhosis and lymphoproliferative disorders. (Letter.) Lancet, 2, 705.

Lennert, K., Stein, H., and Kaiserling, E. (1975a). Cytological and functional criteria for the classification of malignant lymphomata. British Journal of Cancer, 31, supplement, II, 29-43.

Lennert, K., Mohri, N., Stein, H., and Kaiserling, E. (1975b). The histopathology of malignant lymphoma. British Journal of Haematology, 31, supplement, 193203.

Lukes, R. J. and Collins, R. D. (1974). Immunologic characterization of human malignant lymphomas. Cancer (Philadelphia), 34, 1488-1503.

Lukes, R. J. and Collins, R. D. (1975). New approaches to the classification of the lymphomata. British Journal of Cancer, 31, supplement II, 1-28.

Nowoslawski, A., Brzosko, W. J., Madaliński, K., and Krawczyński, K. (1970). Cellular localisation of Australia antigen in the liver of patients with lymphoproliferative disorders. Lancet, 1, 494-498.

Rappaport, H. (1966). Tumors of the Hematopoietic System. (Atlas of Tumor Pathology, Section III, Fascicle 8). Armed Forces Institute of Pathology, Washington, DC.

Ray, M. B. and Desmet, V. J. (1975). Immunofluorescent detection of hepatitis B antigen in paraffin-embedded liver tissue. Journal of Immunological Methods, 6, 283289.

Ray, M. B., Desmet, V. J., Fevery, J., de Groote, J., Bradburne, A. F., and Desmyter, J. (1976a). Hepatitis B surface antigen (HBsAg) in the liver of patients with hepatitis: a comparison with serological detection. Journal of Clinical Pathology, 29, 89-93.

Ray, M. B., Desmet, V. J., Fevery, J., de Groote, J., Bradburne, A. F., and Desmyter, J. (1976b). Distribution patterns of hepatitis B surface antigen ( $\mathrm{HBsAg}$ ) in the liver of hepatitis patients. Journal of Clinical Pathology, 29, 94-100.

Vykoupil, K. F. and Georgii, A. (1972). Uber die fibrosierende Wirkung von Lymphozyten in der Leber bei Lymphadenosen. In Der Lymphozyt, Strukur, Physiologie, Pathologie und Klinik, edited by $\mathrm{H}$. Pietschmann, pp. 199-203. Wiener medizinischen Akademie, Vienna.

Waldenström, J. (1961). Clinical diagnosis and biochemical findings in material of 296 sera with M-type, narrow, $\gamma$ globulins. Acta Medica Scandinavica supplement, 367, 110-119.

Walker, G. (1974). The immunology of liver disorders. In Clinical Immunology and the Physician. Symposium No. 14. Proceedings of the Royal Society of Medicine, 67, 566-573. 